\title{
Expression profile of Eph receptors and ephrin ligands in human skin and downregulation of EphA1 in nonmelanoma skin cancer
}

\author{
Christian Hafner, Bernd Becker, Michael Landthaler and Thomas Vogt \\ Department of Dermatology, University of Regensburg, Regensburg, Germany
}

\begin{abstract}
Eph receptors and ephrin ligands represent the largest family of receptor tyrosine kinases. Beyond their welldefined meaning in developmental processes, these molecules also have important functions in adult human tissues and cancer. However, the Eph/ephrin expression profile in human skin is only marginally studied. We therefore investigated the mRNA expression of 21 Eph receptors and ephrin ligands in adult human skin in comparison to 13 other adult human tissues using quantitative real-time RT-PCR. In addition, immunohistochemistry was established for some members (EphA1, EphA2 and EphA7) to confirm the results of the RT-PCR and to identify the expressing cells in the skin. We found all investigated family members expressed in human skin, but at highly varying levels. EphA1, EphB3 and ephrin-A3 turned out to be most prominently expressed in skin compared to other adult human tissues. EphA1 was exclusively expressed in the epidermis. We therefore investigated the expression of EphA1 in nonmelanoma skin cancers derived from the epidermis (56 basal cell carcinomas and 32 squamous cell carcinomas). As demonstrated by immunohistochemistry, both skin cancers displayed a significant downregulation of EphA1 compared to the normal epidermis. In squamous cell carcinoma, the EphA1 downregulation was associated with increased tumor thickness, although this was not significant. Our results indicate that Eph receptors and ephrin ligands are widely expressed in the adult human skin, particularly in the epidermis, and may play an important role in skin homeostasis. EphA1 seems to be a marker of the differentiated normal epidermis and its downregulation in nonmelanoma skin cancer may contribute to carcinogenesis of these very frequent human tumors. EphA1 represents a new potential prognostic marker and therapeutic target in nonmelanoma skin cancer.
\end{abstract}

Modern Pathology (2006) 19, 1369-1377. doi:10.1038/modpathol.3800660; published online 7 July 2006

Keywords: Eph receptor tyrosine kinase; ephrin; real-time RT-PCR; nonmelanoma skin cancer; EphA1; epidermis

The Eph receptors represent the largest family of receptor tyrosine kinases. Eph receptors and their ephrin ligands are divided into the two subclasses A and $\mathrm{B}$, based on the sequence homology of the extracellular sequence, the structure and the binding affinity. ${ }^{1}$ Fourteen Eph receptors and eight ephrin ligands are currently known in humans. EphA10 has been recently characterized as a novel member of the family. ${ }^{2}$ Both EphA10 and EphB6 lack a tyrosine kinase activity. ${ }^{3}$ Ephrin-A ligands share a glycosyl-phosphatidyl-inositol anchor, while ephrin-B ligands have a transmembrane domain and a short cytoplasmatic tail. Eph receptors and ephrin ligands are membrane-bound, thus direct cell-cellcontacts are required for ligand binding and activa-

Correspondence: Dr C Hafner, MD, Department of Dermatology, University of Regensburg, Franz-Josef-Strauss-Allee 11, Regensburg 93042, Germany.

E-mail: christian.hafner@klinik.uni-regensburg.de

Received 7 February 2006; revised 8 June 2006; accepted 11 June 2006; published online 7 July 2006 tion of intracellular signaling. EphA receptors promiscuously bind ephrin-A ligands, and EphB receptors likewise bind ephrin-B ligands, although the binding affinity between the different members vary considerably. ${ }^{4}$ As an exception, EphA4 can also interact with ephrin-B ligands, and ephrin-A5 can bind to EphB2 at high concentration. ${ }^{5}$ Eph receptors and ephrin ligands form dimers and tetramers, and also aggregate into larger clusters. ${ }^{6}$ Bidirectional signaling is initialized in both the receptor and the ligand bearing cell upon receptor-ligand interaction. ${ }^{7}$ The Eph/ephrin family is differentially expressed in various adult human tissues. ${ }^{8}$ Eph/ephrin signaling between cells affects cell morphology, migration and adhesion of cells. This receptor family is involved in developmental processes, ${ }^{9}$ and seems to play a pivotal role in tissue maintenance throughout life. To date, experimental evidence has been gained for example in the intestinal epithelium, ${ }^{10-12}$ and the immune system. ${ }^{13}$

Eph receptors and ephrins are furthermore differentially expressed in various human cancers. ${ }^{14,15}$ 
Profound distortions of the expression patterns have been correlated with increased invasiveness, metastatic potential and neo-vascularization, thus affecting the outcome of the patients. Successful peptide, antibody and antisense targeting of Eph receptors has even opened the gate for new molecular-targeted therapeutic approaches. ${ }^{16,17}$

However, the expression of Eph receptors and ephrin ligands has not yet been investigated systematically in normal adult human skin. The skin is the largest organ from that the most frequent cancers in mankind arise, basal cell carcinoma and squamous cell carcinoma. We therefore analyzed mRNA expression of this receptor and ligand class in normal human skin, highlighting some specific findings by immunohistochemistry. Since EphA1 was predominantly expressed in the human epidermis at a high level, we investigated the role of this receptor tyrosine kinase in nonmelanoma skin cancer.

\section{Materials and methods}

\section{Isolation of RNA}

The RNA was collected from adult normal human skin samples of 10 donors after written informed consent was obtained. The data of the patients can be obtained from Table 1. In brief, the epidermis and

Table 1 Patients' characteristics

\begin{tabular}{|c|c|c|c|}
\hline Nr. \# & Sex & Age & Localization \\
\hline \multicolumn{4}{|c|}{ Normal skin } \\
\hline 1 & $\mathrm{~m}$ & 48 & Back \\
\hline 2 & $\mathrm{f}$ & 44 & Forearm \\
\hline 3 & $\mathrm{~m}$ & 73 & Back \\
\hline 4 & $\mathrm{f}$ & 52 & Upper arm \\
\hline 5 & $\mathrm{~m}$ & 35 & Back \\
\hline 6 & $\mathrm{f}$ & 63 & Upper arm \\
\hline 7 & $\mathrm{~m}$ & 76 & Upper arm \\
\hline 8 & $\mathrm{f}$ & 30 & Lower leg \\
\hline 9 & $\mathrm{f}$ & 35 & Back \\
\hline 10 & $\mathrm{~m}$ & 66 & Back \\
\hline \multicolumn{4}{|c|}{ Basal cell carcinoma } \\
\hline 1 & $\mathrm{f}$ & 68 & Temple \\
\hline 2 & $\mathrm{~m}$ & 50 & Nose \\
\hline 3 & $\mathrm{f}$ & 79 & Nose \\
\hline 4 & $\mathrm{f}$ & 74 & Nose \\
\hline 5 & $\mathrm{f}$ & 70 & Forehead \\
\hline 6 & $\mathrm{~m}$ & 67 & Back \\
\hline 7 & $\mathrm{~m}$ & 56 & Neck \\
\hline 8 & $\mathrm{~m}$ & 67 & Upper arm \\
\hline 9 & $\mathrm{~m}$ & 56 & Abdomen \\
\hline 10 & $\mathrm{f}$ & 77 & Forehead \\
\hline 11 & $\mathrm{f}$ & 65 & Back \\
\hline 12 & $\mathrm{f}$ & 77 & Forehead \\
\hline 13 & $\mathrm{~m}$ & 61 & Temple \\
\hline 14 & $\mathrm{~m}$ & 68 & Forehead \\
\hline 15 & $\mathrm{~m}$ & 51 & Chest \\
\hline 16 & $\mathrm{~m}$ & 70 & Scalp \\
\hline 17 & $\mathrm{~m}$ & 87 & Ear \\
\hline 18 & $\mathrm{f}$ & 68 & Ear \\
\hline 19 & $\mathrm{~m}$ & 83 & Forehead \\
\hline 20 & $\mathrm{~m}$ & 63 & Ear \\
\hline 21 & $\mathrm{f}$ & 48 & Chest \\
\hline
\end{tabular}

Table 1 Continued

\begin{tabular}{|c|c|c|c|}
\hline Nr. \# & Sex & Age & Localization \\
\hline 22 & $\mathrm{~m}$ & 73 & Leg \\
\hline 23 & $\mathrm{~m}$ & 78 & Nose \\
\hline 24 & $\mathrm{~m}$ & 65 & Forehead \\
\hline 25 & $\mathrm{f}$ & 81 & Cheek \\
\hline 26 & $\mathrm{f}$ & 46 & Forearm \\
\hline 27 & $\mathrm{~m}$ & 47 & Neck \\
\hline 28 & $\mathrm{f}$ & 81 & Nose \\
\hline 29 & $\mathrm{~m}$ & 67 & Back \\
\hline 30 & $\mathrm{~m}$ & 64 & Nose \\
\hline 31 & $\mathrm{f}$ & 66 & Cheek \\
\hline 32 & $\mathrm{~m}$ & 30 & Temple \\
\hline 33 & $\mathrm{f}$ & 42 & Abdomen \\
\hline 34 & $\mathrm{f}$ & 76 & Temple \\
\hline 35 & $\mathrm{~m}$ & 57 & Eyelid \\
\hline 36 & $\mathrm{~m}$ & 72 & Scalp \\
\hline 37 & $\mathrm{f}$ & 75 & Temple \\
\hline 38 & $\mathrm{~m}$ & 88 & Nose \\
\hline 39 & $\mathrm{~m}$ & 74 & Temple \\
\hline 40 & $\mathrm{f}$ & 83 & Forehead \\
\hline 41 & $\mathrm{~m}$ & 67 & Ear \\
\hline 42 & $\mathrm{~m}$ & 76 & Ear \\
\hline 43 & $\mathrm{~m}$ & 73 & Forehead \\
\hline 44 & $\mathrm{~m}$ & 75 & Ear \\
\hline 45 & $\mathrm{f}$ & 64 & Chest \\
\hline 46 & $\mathrm{f}$ & 75 & Back \\
\hline 47 & $\mathrm{~m}$ & 65 & Thigh \\
\hline 48 & $\mathrm{~m}$ & 67 & Temple \\
\hline 49 & $\mathrm{f}$ & 82 & Temple \\
\hline 50 & $\mathrm{f}$ & 76 & Cheek \\
\hline 51 & $\mathrm{f}$ & 79 & Temple \\
\hline 52 & $\mathrm{~m}$ & 61 & Forehead \\
\hline 53 & $\mathrm{~m}$ & 69 & Shoulder \\
\hline 54 & $\mathrm{f}$ & 64 & Forehead \\
\hline 55 & $\mathrm{f}$ & 70 & Cheek \\
\hline 56 & $\mathrm{~m}$ & 86 & Chest \\
\hline \multicolumn{4}{|c|}{ Squamous cell carcinoma } \\
\hline 1 & $\mathrm{~m}$ & 67 & Scalp \\
\hline 2 & $\mathrm{~m}$ & 69 & Temple \\
\hline 3 & $\mathrm{f}$ & 82 & Temple \\
\hline 4 & $\mathrm{~m}$ & 83 & Scalp \\
\hline 5 & $\mathrm{~m}$ & 66 & Ear \\
\hline 6 & $\mathrm{~m}$ & 72 & Nose \\
\hline 7 & $\mathrm{~m}$ & 85 & Ear \\
\hline 8 & $\mathrm{f}$ & 88 & Nose \\
\hline 9 & $\mathrm{~m}$ & 62 & forehead \\
\hline 10 & $\mathrm{~m}$ & 86 & Ear \\
\hline 11 & $\mathrm{~m}$ & 94 & Temple \\
\hline 12 & $\mathrm{~m}$ & 70 & Forehead \\
\hline 13 & $\mathrm{~m}$ & 84 & Chest \\
\hline 14 & $\mathrm{~m}$ & 78 & Forehead \\
\hline 15 & $\mathrm{~m}$ & 73 & Scalp \\
\hline 16 & $\mathrm{~m}$ & 63 & Unknown \\
\hline 17 & $\mathrm{~m}$ & 64 & Hand \\
\hline 18 & $\mathrm{~m}$ & 76 & Cheek \\
\hline 19 & $\mathrm{~m}$ & 56 & Cheek \\
\hline 20 & $\mathrm{~m}$ & 60 & Forearm \\
\hline 21 & $\mathrm{~m}$ & 67 & Ear \\
\hline 22 & $\mathrm{~m}$ & 79 & Cheek \\
\hline 23 & $\mathrm{f}$ & 79 & Hand \\
\hline 24 & $\mathrm{f}$ & 75 & Cheek \\
\hline 25 & $\mathrm{~m}$ & 67 & Ear \\
\hline 26 & $\mathrm{~m}$ & 83 & Forehead \\
\hline 27 & $\mathrm{f}$ & 58 & Forearm \\
\hline 28 & $\mathrm{~m}$ & 74 & Scalp \\
\hline 29 & $\mathrm{f}$ & 62 & Forehead \\
\hline 30 & $\mathrm{~m}$ & 82 & Temple \\
\hline 31 & $\mathrm{~m}$ & 46 & Bottom lip \\
\hline 32 & $\mathrm{~m}$ & 68 & Ear \\
\hline
\end{tabular}


upper dermis (stratum papillare and upper stratum reticulare) were dissected from the skin tissue specimen at $-20^{\circ} \mathrm{C}$ to avoid RNA degradation and submersed in RLT buffer (Qiagen, Hilden, Germany). Additional sections of the tissue samples were H\&E stained after dissection to control the depth of dissection. After disruption with a mortar and pestle, the samples were shredded in a Qiagen shredder column for homogenization. The RNA isolation was performed according to the protocol of the RNeasy Mini Kit (Qiagen). RNA quality and quantity were assessed using the Agilent 2100 bioanalyzer (Agilent Technologies, Palo Alto, USA). For further RT-PCR analysis, the samples of the 10 donors were pooled to minimize interindividual variability. The mRNA expression of the Eph receptors and ephrin ligands in adult human skin was compared to the mRNA expression of 13 normal adult human tissues (brain, lung, liver, spleen, colon, small intestine, kidney, bladder, prostate, testis, uterus, thymus and bone marrow), which were analyzed previously. ${ }^{8}$

\section{Real-Time RT-PCR}

First strand cDNA was synthesized using the Reverse Transcription Kit from Promega (Madison, USA), according to the manufacturer's protocol. TaqMan ${ }^{\mathbb{R}}$ real-time RT-PCR was performed on an ABI Prism 7900 HT Sequence Detection System (PE Applied Biosystems, Darmstadt, Germany) for quantitation of the transcribed gene specific RNA as described previously. ${ }^{8}$ VIC labeled eukaryotic $18 \mathrm{~S}$ rRNA TaqMan ${ }^{\circledR}$ predeveloped assays were used as an endogenous control (Applied Biosystems). Probes and primers for TaqMan ${ }^{\mathbb{R}}$ analysis of all Eph receptors and ephrin ligands are described elsewhere. ${ }^{8}$ In addition, a predeveloped commercial assay was used for the analysis of EphA5 expression (Applied Biosystems). The standard curve method was used to determine the relative amount of gene expression products. Of the 14 investigated tissues, the one displaying the lowest expression of each investigated mRNA was set as the calibrator and each normalized value was divided by this calibrator resulting in figures representing the $x$-fold mRNA amount compared to this calibrator.

\section{Immunohistochemistry}

For the immunohistochemical analysis of EphA1 protein expression in basal cell carcinomas and squamous cell carcinomas, paraffin embedded tissue specimen of 56 basal cell carcinomas and 32 squamous cell carcinomas were retrieved from the histology files of the Department of Dermatology, University of Regensburg. The patients' characteristics can be seen in Table 1. Sections $(1.5 \mu \mathrm{m})$ of the paraffin embedded tissues were deparaffinized and rehydrated. The sections were then incubated in citrate buffer $(\mathrm{pH}=6)$ at $90^{\circ} \mathrm{C}$ for $40 \mathrm{~min}$. After washing with $\mathrm{H}_{2} \mathrm{O}$ and $\mathrm{PBS}$, the sections were blocked with $2 \% \mathrm{H}_{2} \mathrm{O}_{2} / \mathrm{CH}_{3} \mathrm{OH}$ at $4^{\circ} \mathrm{C}$ for $30 \mathrm{~min}$. The slides were then washed again with $\mathrm{H}_{2} \mathrm{O}$ and incubated with horse serum for $20 \mathrm{~min}$ to suppress nonspecific binding. Then the samples were incubated with the primary antibody dilution at $4^{\circ} \mathrm{C}$ overnight (EphA1 antibody 1:50 from R\&D Systems, Minneapolis, USA). Staining was performed using the Zyto Chem Plus HRP Broad Spectrum Kit (Zytomed, Berlin), according to the manufacturer's protocol. Leaving out the primary antibody served as a negative control. The normal epidermis and the tumor (basal cell carcinoma or squamous cell carcinoma) of each section were separately scored for the expression of EphA1 on a scale between 0 (negative expression) and 4 (very strong expression). Immunohistochemical staining of the normal epidermis for EphA2 (1:100 from Upstate, Lake Placid, USA) and EphA7 (1:100 from Santa Cruz, California, USA) were performed likewise. In addition, 10 sections of skin ulcers were retrieved from our histology files and stained for EphA1 to investigate the expression of this receptor in epidermal wound healing.

\section{Statistical Analysis}

The Wilcoxon test for matched pairs and the nonparametric Mann-Whitney test were used for statistical analysis of the data.

\section{Results}

\section{Eph-Receptor and Ephrin mRNA Expression Profile in Normal Human Skin}

The quantitative mRNA gene expression profile of all known Eph receptors and ephrin ligands (except the recently characterized receptor EphA10) was investigated in normal human skin (epidermis and upper dermis) using real-time RT-PCR. The relative Eph receptor and ephrin mRNA expression in human skin was compared to thirteen different adult human tissues described previously. ${ }^{8}$ According to the standard curve method, the mRNA expression values of each tissue are shown as the $x$-fold expression relative to the calibrator tissue. The tissue displaying the lowest expression of a receptor or ligand is designated as the calibrator (value 1.0). The results of the mRNA expression of all receptors and ligands in human skin and 13 other adult human tissues are displayed in Table 2. For the estimation of the absolute mRNA expression levels, the corresponding $C_{\mathrm{T}}$-value ranges of each tissue are additionally indicated by different background colors in the table.

All investigated Eph receptors and ephrin ligands were expressed in normal adult human skin. Even EphA8 and ephrin-A2, which fail to be expressed in 
Table 2 Eph/ephrin mRNA profile

\begin{tabular}{|c|c|c|c|c|c|c|c|c|c|c|c|c|c|c|c|c|c|c|c|c|c|}
\hline & EphA1 & EphA2 & EphA3 & EphA4 & EphA5 & EphA6 & EphA7 & EphA8 & e-A1 & e-A2 & e-A3 & e-A4 & e-A5 & EphB1 & EphB2 & EphB3 & EphB4 & EphB6 & e-B1 & e-B2 & e-B3 \\
\hline Skin & 19.0 & 16.9 & 1.4 & 32.9 & 44.6 & 111.8 & 131.4 & 1.0 & 8.5 & 1.5 & 816.6 & 18.6 & 29.2 & 4.8 & 1.4 & 82.1 & 4.5 & 69.2 & 6.6 & 5.6 & 30.5 \\
\hline Brain & 2.8 & 2.4 & 28.7 & 136.2 & 553.6 & 882.4 & 1196.6 & 46.3 & 5.7 & 27.5 & 247.4 & 1.0 & 41.5 & 16.2 & 18.7 & 40.9 & 1.0 & 60.5 & 1.2 & 8.5 & 112.9 \\
\hline Lung & 7.6 & 12.2 & 40.8 & 27.6 & 10.9 & 13.6 & 106.6 & $\mathrm{NE}$ & 34.4 & $\mathrm{NE}$ & 3.8 & 10.2 & 18.3 & 3.2 & 13.8 & 39.3 & 16.9 & 18.1 & 7.5 & 23.9 & 9.6 \\
\hline Liver & 8.4 & 5.9 & 18.9 & 1.0 & $\mathrm{NE}$ & 1.1 & 1.0 & $\mathrm{NE}$ & 24.2 & 35.1 & 2.2 & 3.5 & 1.6 & 1.2 & 1.6 & 1.0 & 4.8 & 2.8 & 1.4 & 1.5 & 6.0 \\
\hline Spleen & 2.6 & 7.5 & 15.2 & 15.3 & 25.2 & 1.0 & 323.6 & 33.3 & 1.5 & $\mathrm{NE}$ & 1.0 & 5.0 & 22.0 & 2.3 & 6.6 & 4.2 & 5.4 & 9.8 & 3.4 & 5.1 & 1.0 \\
\hline Colon & 8.9 & 17.8 & 4.1 & 13.8 & NE & 697.0 & 867.0 & $\mathrm{NE}$ & 28.6 & 154.2 & 98.6 & 23.1 & 11.8 & 8.9 & 101.9 & 44.7 & 7.9 & 1.0 & 7.4 & 20.0 & 2.4 \\
\hline Small Intestinum & 9.5 & 8.0 & 24.8 & 12.9 & 5.9 & 33.4 & 310.4 & $\mathrm{NE}$ & 5.5 & 56.5 & 1.8 & 5.9 & 5.9 & 2.2 & 79.4 & 17.8 & 3.7 & 5.3 & 4.4 & 7.6 & 7.8 \\
\hline Kidney & 9.1 & 15.0 & 9.2 & 35.5 & 26.0 & 103.5 & 1413.2 & $\mathrm{NE}$ & 12.7 & 3.0 & 2.4 & 5.7 & 26.7 & 4.1 & 13.4 & 11.5 & 6.3 & 8.6 & 4.8 & 11.4 & 6.6 \\
\hline Bladder & 14.8 & 18.5 & 99.2 & 16.3 & 24.1 & 114.2 & 1090.8 & $\mathrm{NE}$ & 15.0 & 82.4 & 3.2 & 7.8 & 20.9 & 2.5 & 8.1 & 13.9 & 6.9 & 11.0 & 9.4 & 6.1 & 4.0 \\
\hline Prostate & 5.1 & 4.2 & 82.1 & 9.1 & 227.0 & 85.4 & 763.7 & NE & 11.5 & 1.0 & 18.8 & 6.2 & 9.0 & 2.2 & 3.0 & 23.0 & 3.5 & 19.4 & 1.9 & 4.5 & 11.5 \\
\hline Testis & 4.7 & 4.5 & 38.8 & 92.3 & 29.9 & 2251.5 & 991.4 & 88.7 & 4.2 & 13.5 & 43.4 & 4.3 & 16.1 & 13.9 & 15.0 & 8.9 & 6.6 & 35.8 & 3.7 & 7.9 & 20.4 \\
\hline Uterus & 1.3 & 8.2 & 126.8 & 19.3 & 53.9 & 149.3 & 365.1 & $\mathrm{NE}$ & 7.8 & $\mathrm{NE}$ & 4.0 & 3.7 & 5.0 & 2.9 & 4.2 & 25.7 & 7.5 & 20.1 & 3.3 & 4.0 & 29.1 \\
\hline Thymus & 8.1 & 4.6 & 4.0 & 15.2 & 2.0 & 3.6 & 15.2 & $\mathrm{NE}$ & 4.5 & $\mathrm{NE}$ & 8.3 & 4.9 & 5.0 & 1.4 & 4.3 & 5.9 & 1.3 & 110.5 & 1.8 & 2.7 & 3.5 \\
\hline Bone Marrow & 1.0 & 1.0 & 1.0 & 3.9 & 1.0 & 3.3 & 1.1 & $\mathrm{NE}$ & 1.0 & NE & 1.1 & 1.7 & 1.0 & 1.0 & 1.0 & 1.3 & 1.3 & 6.9 & 1.0 & 1.0 & 2.8 \\
\hline
\end{tabular}

\begin{tabular}{|c|c|c|c|c|}
\hline & not expr & ssed & & strong expressed \\
\hline t-value & 45 & $44-35$ & $34-32$ & $31-29$ \\
\hline
\end{tabular}

The mRNA expression of Eph receptors and ephrin ligands in normal adult human skin was investigated relative to 13 other adult human tissues described previously. ${ }^{8}$ For each single Eph receptor and ephrin ligand (in a column), the tissue with the lowest mRNA expression is designated as the calibrator (value 1.0). For each tissue, the relative mRNA amount is indicated as the $x$ fold amount compared to the calibrator (fold change). The tissue with the highest expression is indicated (bold type). Furthermore, the $C_{\mathrm{T}}$ value ranges of each tissue (mean values of three fold amount compared to the calibrator (fold change). The tissue with the highest expression is indicated (bold type). Furthermore, the $C_{\mathrm{T}}$ value ranges of each tissue (mean values of three
reactions) are displayed by different background colors. The $\mathrm{C}_{\mathrm{T}}$ values allow to estimate the absolute amount of the expressed target genes in the tissues and to compare the mRNA expression of different Eph and ephrin members in the same tissue. However, it has to be considered that the $C_{\mathrm{T}}$ values are not normalized to the endogenous control and the amplification efficacy of the single different Eph and ephrin members in the same tissue. However, it has to 
many human tissues according to our previous study, ${ }^{8}$ are expressed in human skin at low levels. EphA1 displays the highest relative mRNA expression in the skin compared to the other 13 tissues. EphA2 and EphA4 show the highest absolute expression levels of EphA receptors and are strongly expressed in human skin. The absolute expression levels of EphA6 and EphA7 are higher than the levels of EphA3 and EphA5. Among ephrin-A ligands, ephrin-A3 displays the highest expression in the skin relative to the other tissues, but ephrinA1, ephrin-A4 and ephrin-A5 are also expressed at relatively high levels. Ephrin-A5 shows the highest absolute expression of A-ephrins in the skin according to the corresponding $C_{\mathrm{T}}$-values. In the subgroup of B-receptors, EphB3 is the most prominent member in the skin. EphB3 displays not only the highest relative mRNA expression in this tissue compared to the other 13 tissues, but also show a high absolute expression level. EphB1 and particularly EphB2 display lower absolute mRNA levels in the skin. Interestingly, in our study, human skin had the second highest EphB6 mRNA expression after the thymus. The three ephrin-B ligands are also quite prominently expressed in skin. The absolute expression of ephrin-B1 and B2 in the skin was higher than ephrin-B3 according to the corresponding $C_{\mathrm{T}}$-values. Nevertheless, the skin was the organ with the third highest ephrin-B3 mRNA expression after brain and uterus.

Immunohistochemical analysis of EphA1 protein revealed its almost exclusive expression in the keratinocytes of the epidermis and hair follicles, whereas in dermal cells (fibroblasts, vascular cells, and inflammatory cells) no EphA1 expression could be detected. As a typical cell-surface receptor, the staining of EphA1 was accentuated at the outer membranes of keratinocytes rather than in the cytoplasm (Figure 1a). Similar results were found for EphA2 (Figure 1b). In contrast, EphA7 expression was restricted to the basal membrane zone of the epidermis as well as blood vessels and nerve fibers of the dermis (Figure 1c).

\section{Expression of EphA1 in Non-Melanoma Skin Cancer}

Since a role in tumorigenesis has been frequently attributed to Eph receptors and EphA1 seems to be one of the most important Eph members in skin, we also investigated possible changes of EphA1 expression in epithelial skin cancer. Immunohistochemistry for EphA1 was assessed in 56 basal cell carcinomas and 32 squamous cell carcinomas. For each sample, the tumor (basal cell carcinoma or squamous cell carcinoma) and the adjacent normal epidermis were separately scored for EphA1 protein expression on a scale ranging from 0 (no expression) to 4 (very strong expression). In the series of 56 basal cell carcinomas, the tumors displayed a significant lower EphA1 expression than the corresponding normal epidermis. The mean values of the EphA1 expression scores were $2.77 \pm 0.95$ for the normal epidermis and $2.11 \pm 1.06$ for the basal cell carcinomas $(P<0.01)$ (Figures $1 \mathrm{~d}$ and 2$)$. This suggests that EphA1 is a marker for normal differentiation of the epidermis, which is reduced or lost in 'basal cell'like differentiated epidermal tumors. Interestingly, while typical basal cell carcinomas retain some EphA1 expression, an example of a more poorly differentiated spindle cell component of basal cell carcinoma was completely lacking EphA1 (Figure 1e).

EphA1 expression was also significantly reduced in squamous cell carcinoma. The mean values were $1.84 \pm 0.88$ for the normal epidermis and $1.34 \pm 0.97$ for the squamous cell carcinomas $(P<0.01)$ (Figures If and 3). Since the thickness of the tumor is an important prognostic parameter in squamous cell carcinoma, we compared the reduction of EphA1 expression and the tumor thickness (Figure 4). Although the loss of EphA1 protein expression in squamous cell carcinoma increases with tumor thickness, this correlation was not significant in our series.

\section{Expression of EphA1 in Skin Ulcers}

Since previous studies suggested a role for Eph/ ephrin signaling in epithelial wound closure and regeneration, we stained a series of 10 skin ulcers for EphA1 protein. Some sections of this preliminary series revealed an interesting change of the staining pattern: Distant from the rim of the ulcers, the typical network pattern of an intact epidermis can be seen, which probably results from EphA1 compartimentalization in the plasma membrane of the keratinocytes. Close to the rim, the network was replaced by a less structured pattern, which is due to a more diffuse and partly intracytoplasmatic staining of EphA1 (Figure 5). Completely reconstituted epidermis covering the dermal scar tissue again displayed the reestablished network pattern.

\section{Discussion}

The knowledge of the Eph receptor and ephrin expression profile is a major prerequisite in order to unravel the role of Eph/ephrin signaling in human skin with possible impact on wound healing, tissue engineering and carcinogenesis. In the adult human skin, Eph/ephrin expression is only marginally known. EphA1, for example, has been reported to be expressed mainly in epithelial tissues including the skin. ${ }^{18}$ EphA2, EphA7 and EphB3 are expressed in Langerhans cells of the skin. ${ }^{19}$ In the latter study, EphA2, ephrin-A3, ephrin-B1 and ephrin-B2 were also detected in keratinocytes.

To our knowledge, this is the first comprehensive study of mRNA expression of all members of the Eph/ephrin family in adult human skin. The results 

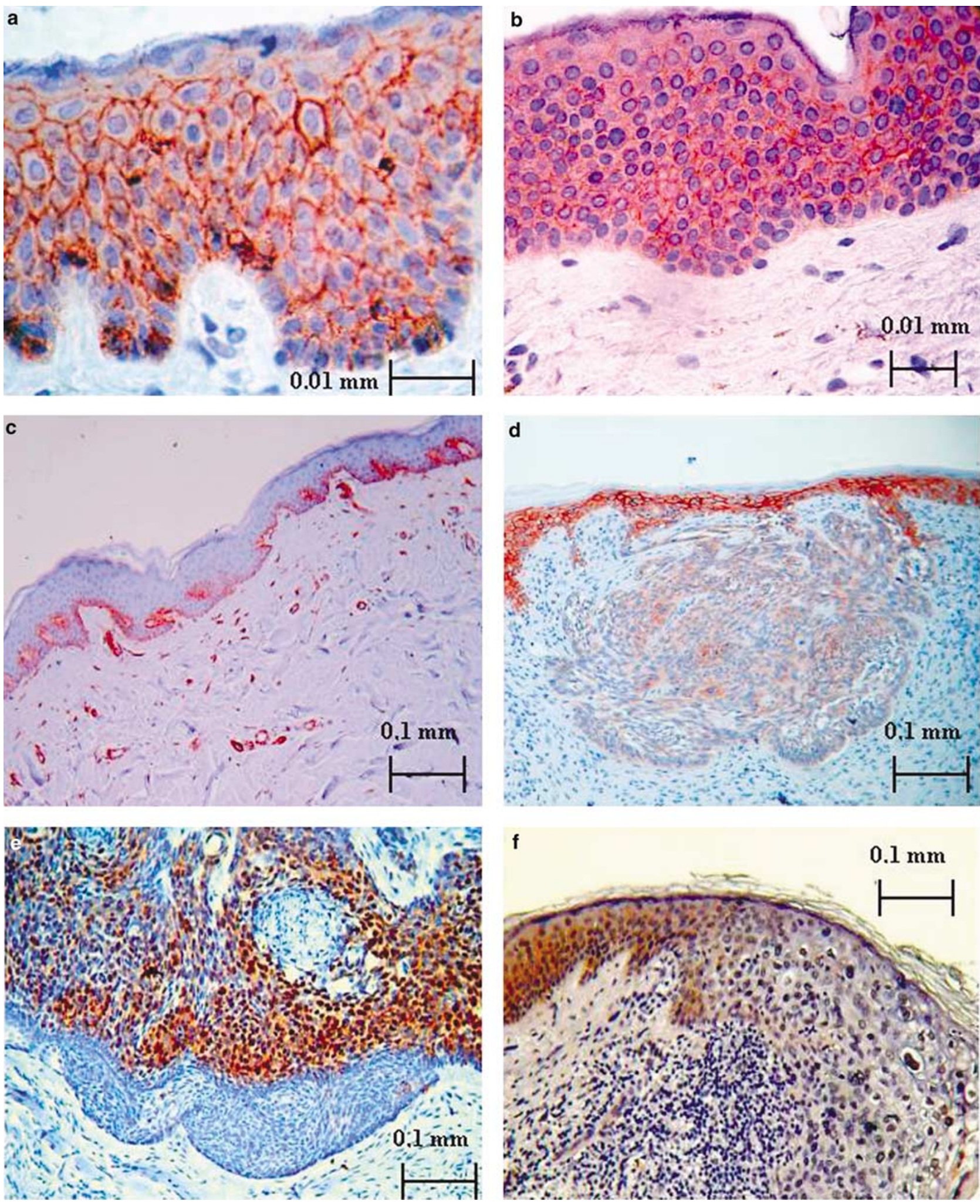

Figure 1 (a) Immunohistochemical staining for EphA1 shows expression in the epidermis with an accentuation at the outer membrane of the keratinocytes. (b) Immunohistochemistry for EphA2 displays exclusive expression of this receptor tyrosine kinase in the epidermis. (c) Immunohistochemical staining for EphA7 shows expression of this receptor at the basal membrane zone of the epidermis and positive staining of the blood vessels and nerve fibers (not shown) in the dermis. (d) Immunohistochemical staining for EphA1 shows a loss of EphA1 expression in the basal cell carcinoma compared to the normal epidermis. (e) Immunohistochemistry for EphA1 reveals two components in a basal cell carcinoma, a typical basaloid component expressing EphA1 and a more poorly differentiated spindle cell component completely lacking EphA1. (f) Immunohistochemical staining for EphA1 shows EphA1 expression in the normal epidermis, but loss of EphA1 expression in the adjacent squamous cell carcinoma (carcinoma in situ). 


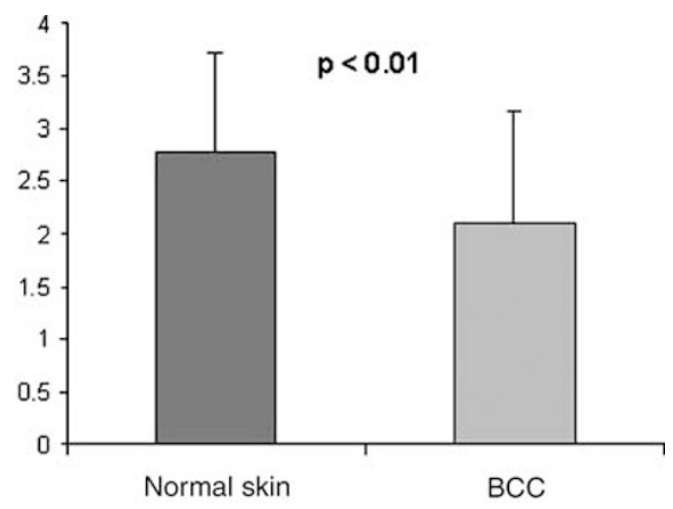

Figure 2 The mean values of the EphA1 expression scores of normal epidermis and basal cell carcinomas $(n=56)$ show that EphA1 expression is significantly reduced in basal cell carcinoma $(P<0.01)$. The EphA1 expression assessed by immunohistochemistry was scored on a scale ranging from 0 (no expression) to 4 (very strong expression).

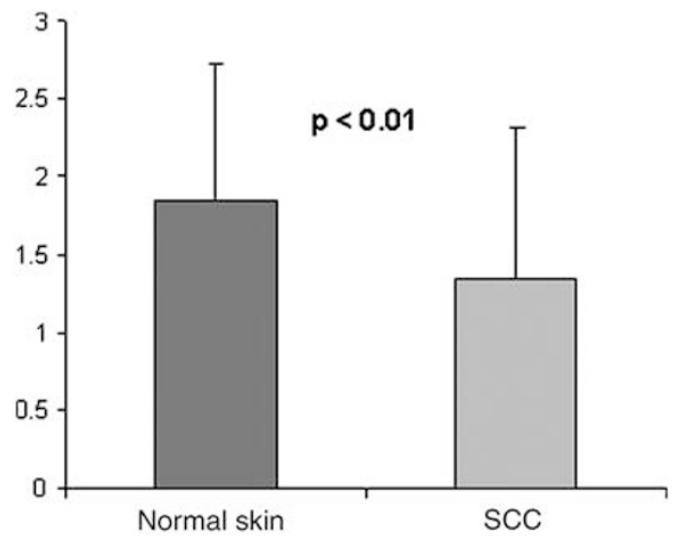

Figure 3 The mean values of the EphA1 expression scores of normal epidermis and squamous cell carcinomas $(n=32)$ show that EphA1 expression is significantly reduced in squamous cell carcinoma $(P<0.01)$. The EphA1 expression assessed by immunohistochemistry was scored on a scale ranging from 0 (no expression) to 4 (very strong expression). reveal a specific repertoire of Eph receptors and ephrin ligands for this tissue. EphA1, EphB3 and ephrin-A3 displayed a peak expression in skin when compared to other adult human tissues. EphA2, EphA4, EphB4, EphB6, ephrin-A4, ephrin-A5, ephrin-B1, ephrin-B2 and ephrin-B3 are also among the members showing a prominent expression in skin. Although the complexity of possible cell-cell communications in skin mediated by Eph/ephrin signaling is staggering, this may reflect a pivotal physiological role of these receptors and ligands in skin homeostasis.

One major task of skin is to provide rapid wound closure and some of the detected family members may be involved in those pathways. The ligand ephrin-A4, for example, is mainly expressed in rat epidermis and inhibits the sprouting of cutaneous nerves during embryogenesis. Vice versa, in neonatal skin wounds of rats, ephrin-A4 is downregulated and allows therefore sensory hyperinnervation of the wounded skin area. ${ }^{20}$ In another epithelial barrier tissue, the intestinal epithelium, particularly EphB/ ephrin-B2 signaling seems to be involved into the induction of a wound healing phenotype and the rapid closure of epithelial defects, ${ }^{11,12}$ but it is not known whether ephrin-B2 can play a similar role in wounded skin. We observed a differential expression pattern of EphA1 protein in keratinocytes of the rim of skin ulcers compared to keratinocytes distant from the rim. These preliminary observations may be explained by receptor internalization and cytoplasmic trafficking of EphA1 in cells close to the rim of epidermal defects. Microendocytosis of Eph-ephrin complexes upon Eph-ephrin mediated cell-cell signaling has already been reported for EphB4 and ephrin-B2 in fibroblasts. ${ }^{21}$ It is also important to note that additional mechanisms like differential phosphorylation/activation of receptors may be involved in epidermal wound closure, which can be not detected by simple immunohistochemistry of EphA1.

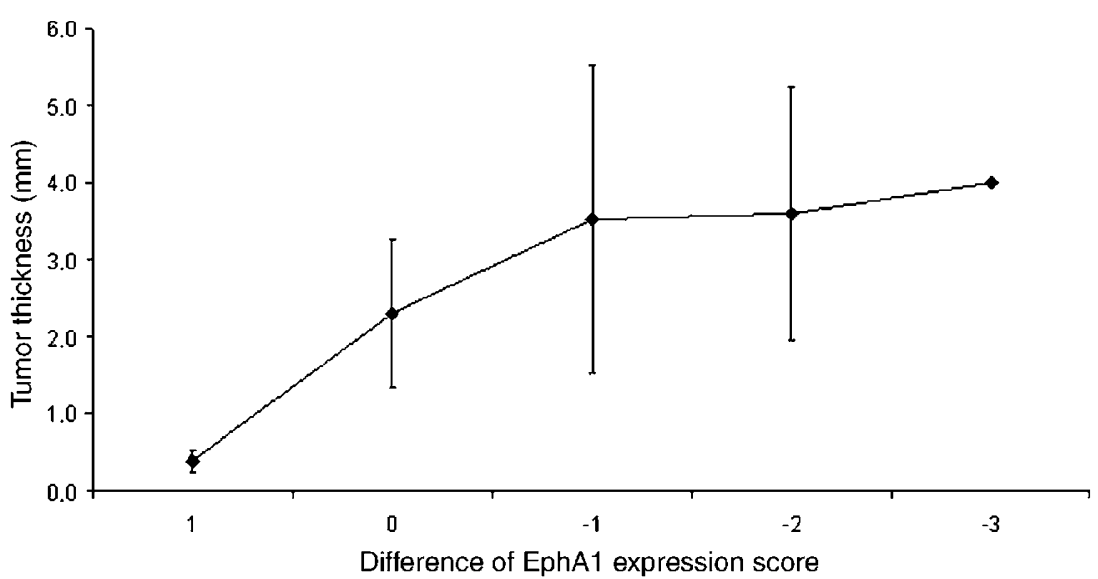

Figure 4 Comparison of the reduction of EphA1 expression and the mean values of tumor thickness of squamous cell carcinomas $(n=32)$. The loss of EphA1 protein expression in squamous cell carcinoma increases with tumor thickness, but this correlation was not significant in our series (difference of EphA1 expression score $=$ expression score of the squamous cell carcinoma-expression score of the corresponding normal epidermis). The EphA1 expression assessed by immunohistochemistry was scored on a scale ranging from 0 (no expression) to 4 (very strong expression). 

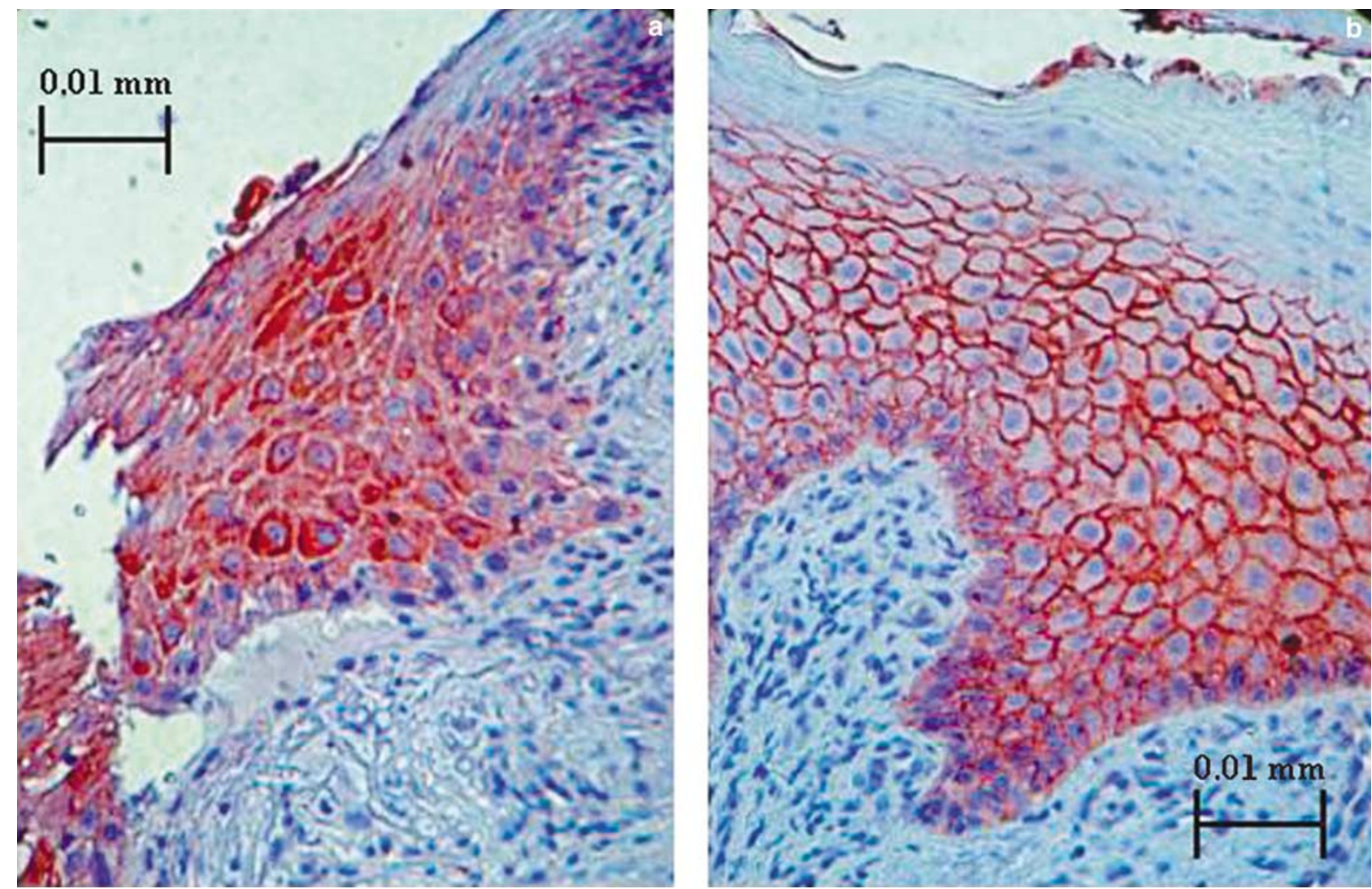

Figure 5 Immunohistochemistry for EphA1 of skin ulcers. (a) Keratinocytes adjacent to the rim of the ulcer show an intense cytoplasmic staining pattern. (b) Keratinocytes distant from the rim of the same ulcer show the typical network staining pattern of EphA1, caused by an accentuated expression of this receptor at the membrane of the keratinocytes.

Some members like EphA1 and EphA2 are predominantly expressed in the epidermis. In contrast, EphA7 expression was detected in the basal membrane zone of the epidermis as well as in blood vessels and nerve fibers of the upper dermis. EphA7 expression in blood vessels was already reported in the kidney and liver. ${ }^{8}$ A functional role of this member in the vasculature and nerve fibers of the skin has to be further investigated, but a potential role in angiogenesis and dermal wound healing seems possible. In a mouse skin model, hypoxia could induce upregulation of some Eph/ ephrin members. ${ }^{22}$ Interestingly, EphB6 is strongly expressed in the skin. Since EphB6 displays its highest expression the thymus ${ }^{8}$ and EphB6 signaling was shown to be important for T-cell function, ${ }^{13,23,24}$ this particular receptor may be related to immunologic functions of T-cells in skin.

Since Eph receptor expression is often disrupted in tumorigenesis, ${ }^{15}$ we also investigated possible changes of Eph receptor expression in nonmelanoma skin cancer. Both basal cell carcinoma and squamous cell carcinoma showed a significant downregulation of EphA1 protein, which is strongly expressed in the normal epidermis. This would be compatible with EphA1 as a marker of differentiation in the human epidermis. Downregulation of specific Eph members is exceptional in cancer, since many more examples document overexpression, which is sometimes related to cancer progression and prognosis of the patients. However, loss of Eph receptor expression has also been described in some tumors, for example, EphB4 in breast cancer $^{25}$ and EphB6 in metastatic melanoma. ${ }^{26}$ In neuroblastoma, re-expression of EphB6 in tumor cells significantly suppressed their tumorigenicity. ${ }^{27}$ Downregulation of EphA1 in malignant tumors has been previously described in human glioblastoma ${ }^{8}$ and human breast carcinoma cell lines. ${ }^{28}$ In the breast carcinoma cells, this downregulation in concert with a dysregulation of other Eph/ephrins is associated with a more aggressive and invasive behavior of the cells. In our study, the loss of EphA1 was associated with the prognostic relevant tumor thickness. Tumors with a stronger downregulation of EphA1 tended to show an increased thickness. However, this trend was not significant in our series, which may be due to limited sample numbers.

Further investigation of the physiological role of EphA1 and other family members in the normal epidermis and nonmelanoma skin cancer is required to define the role of Eph/ephrins in skin homeostasis and carcinogenesis. EphA1 and other prominently expressed family members represent 
potential new prognostic parameters and therapeutic targets for the treatment of various benign and malignant skin disorders.

\section{Acknowledgements}

We thank Lydia Künzel, Nadine Wandtke and Petra Weiderer for excellent technical support. This work was supported by the Reform A grant of the University of Regensburg, Germany.

\section{References}

1 Eph Nomenclature Committee. Unified nomenclature for Eph family receptors and their ligands, the ephrins. Cell 1997;90:403-404.

2 Aasheim HC, Patzke S, Hjorthaug HS, et al. Characterization of a novel Eph receptor tyrosine kinase, EphA10, expressed in testis. Biochim Biophys Acta 2005;1723:1-7.

3 Gurniak CB, Berg LJ. A new member of the Eph family of receptors that lacks protein tyrosine kinase activity. Oncogene 1996;13:777-786.

4 Pasquale EB. Eph-ephrin promiscuity is now crystal clear. Nat Neurosci 2004;7:417-418.

5 Himanen JP, Chumley MJ, Lackmann M, et al. Repelling class discrimination: ephrin-A5 binds to and activates EphB2 receptor signaling. Nat Neurosci 2004;7:501-509.

6 Pasquale EB. Eph receptor signalling casts a wide net on cell behaviour. Nat Rev Mol Cell Biol 2005;6: $462-475$.

7 Bruckner K, Klein R. Signaling by Eph receptors and their ephrin ligands. Curr Opin Neurobiol 1998;8: 375-382.

8 Hafner C, Schmitz G, Meyer S, et al. Differential gene expression of Eph receptors and ephrins in benign human tissues and cancers. Clin Chem 2004;50: 490-499.

9 Pasquale EB. The Eph family of receptors. Curr Opin Cell Biol 1997;9:608-615.

10 Batlle E, Henderson JT, Beghtel H, et al. Beta-catenin and TCF mediate cell positioning in the intestinal epithelium by controlling the expression of EphB/ ephrinB. Cell 2002;111:251-263.

11 Hafner C, Meyer S, Hagen I, et al. Ephrin-B reverse signaling induces expression of wound healing associated genes in IEC-6 intestinal epithelial cells. World J Gastroenterol 2005;11:4511-4518.

12 Hafner C, Meyer S, Langmann T, et al. Ephrin-B2 is differentially expressed in the intestinal epithelium in Crohn's disease and contributes to accelerated epithelial wound healing in vitro. World J Gastroenterol 2005;11:4024-4031.
13 Luo H, Yu G, Wu Y, et al. EphB6 crosslinking results in costimulation of $\mathrm{T}$ cells. J Clin Invest 2002;110: 1141-1150.

14 Nakamoto M, Bergemann AD. Diverse roles for the Eph family of receptor tyrosine kinases in carcinogenesis. Microsc Res Tech 2002;59:58-67.

15 Surawska H, Ma PC, Salgia R. The role of ephrins and Eph receptors in cancer. Cytokine Growth Factor Rev 2004;15:419-433.

16 Carles-Kinch K, Kilpatrick KE, Stewart JC, et al. Antibody targeting of the EphA2 tyrosine kinase inhibits malignant cell behavior. Cancer Res 2002;62: 2840-2847.

17 Koolpe M, Dail M, Pasquale EB. An ephrin mimetic peptide that selectively targets the EphA2 receptor. J Biol Chem 2002;277:46974-46979.

18 Coulthard MG, Lickliter JD, Subanesan N, et al. Characterization of the Epha1 receptor tyrosine kinase: expression in epithelial tissues. Growth Factors 2001; 18:303-317.

19 De Saint-Vis B, Bouchet C, Gautier G, et al. Human dendritic cells express neuronal Eph receptor tyrosine kinases: role of EphA2 in regulating adhesion to fibronectin. Blood 2003;102:4431-4440.

20 Moss A, Alvares D, Meredith-Middleton J, et al. Ephrin-A4 inhibits sensory neurite outgrowth and is regulated by neonatal skin wounding. Eur J Neurosci 2005;22:2413-2421.

21 Marston DJ, Dickinson S, Nobes CD. Rac-dependent trans-endocytosis of ephrinBs regulates Eph-ephrin contact repulsion. Nat Cell Biol 2003;5:879-888.

22 Vihanto MM, Plock J, Erni D, et al. Hypoxia upregulates expression of Eph receptors and ephrins in mouse skin. FASEB J 2005;19:1689-1691.

23 Freywald A, Sharfe N, Rashotte C, et al. The EphB6 receptor inhibits JNK activation in T lymphocytes and modulates $\mathrm{T}$ cell receptor-mediated responses. J Biol Chem 2003;278:10150-10156.

24 Luo H, Wan X, Wu Y, et al. Cross-linking of EphB6 resulting in signal transduction and apoptosis in Jurkat cells. J Immunol 2001;167:1362-1370.

25 Berclaz G, Flutsch B, Altermatt HJ, et al. Loss of EphB4 receptor tyrosine kinase protein expression during carcinogenesis of the human breast. Oncol Rep 2002; 9:985-989.

26 Hafner C, Bataille F, Meyer S, et al. Loss of EphB6 expression in metastatic melanoma. Int J Oncol 2003; 23:1553-1559.

27 Tang XX, Zhao H, Robinson ME, et al. Implications of EPHB6, EFNB2, and EFNB3 expressions in human neuroblastoma. Proc Natl Acad Sci USA 2000;97: 10936-10941.

28 Fox BP, Kandpal RP. Invasiveness of breast carcinoma cells and transcript profile: Eph receptors and ephrin ligands as molecular markers of potential diagnostic and prognostic application. Biochem Biophys Res Commun 2004;318:882-892. 